\title{
Improving primary health care through technological innovation
}

\author{
Peter P. Groenewegen and Jack B.F. Hutten \\ Netherlands Institute of Primary Health Care (NIVEL), Utrecht, The Netherlands
}

Accepted 28 September 1989

\section{Summary}

As a result of policy changes and developments on the demand side, the Importance of technology in primary health care will grow fast. An approach to the implementation of new technologies in primary health care is presented in this article. First we describe the main problems in Dutch primary health care. The second step is to identify new technologies which are becoming available. Subsequently, the interface between these problems and their possible technological resolution has to be found. The fact that a technological innovation appears to be a solution is not sufficient reason for introducing it. There are all kinds of reasons why an innovation that has proved useful in the hospital situation, for example, might be of doubtful use in primary health care. Accordingly, the next step is to assess whether a technological solution to a problem in primary health care is indeed an improvement. To acknowledge the particular situation of primary health care, a scheme has been developed that may be used to determine criteria of evaluation.

Technology, Primary health care; Evaluation

\section{Introduction}

Advanced technologies are mostly applied in specialist health care, especially in the hospital setting. Primary health care providers, such as general practitioners and community nurses, do not commonly use advanced technologies. Their work is generalist in character, and they are not trained to make use of complicated techniques and equipment. Primary health care and technological innovation are

Address for correspondence: Dr. Peter P. Groenewegen, NIVEL, P.O. Box 1568, 3500 BN Utrecht, The Netherlands 
therefore usually not strongly associated with each other.

It is likely that this situation in the Netherlands will change in the near future. First, there is a shift in Dutch health policy in favour of home care instead of hospital care (substitution). This makes the implementation of more advanced technologies at home necessary (demand pull). Secondly, there is the technology push of more technologies becoming available for primary care providers: not only medical technologies but also other kinds, for example information technologies like computer networks.

Most medical technologies are developed originally for specialist (hospital) care. They devolve from central research and teaching hospitals to community hospitals and to community practice. Workers in primary health care normally do not take the initiative in technological innovation. They use techniques which are developed and tested in another part of medicine. The diffusion of technology to primary health care is mainly unintended and unanticipated.

It should be noted, however, that technological innovation has not necessarily the same outcome and consequences in primary care as in hospital care. Both settings differ from each other in many ways. Differences in patient selection and prevalence of the disease may affect the outcome of medical technology [1]. Primary care is much less organized, the providers are less technology minded, and the social and human implications of the use of a technology may be different in community care because care is provided directly in the patients' daily life: it can for example also affect the family and other informal carers. The effectiveness of medical technologies might therefore have to be re-established or re-evaluated, and other aspects of the implementation of a technology will have to be assessed.

Because of the growing significance of technology in primary health care, we have to consider another, more rational, approach to the introduction of technology in this sector of health care. The central question of this paper is what a more rational approach to the introduction of new technology in primary health care might look like. We propose a stepwise approach which starts with the description of the main problems in primary health care. The second step is to identify the new technologies which become available. The next step again is to define the interface between problems and their possible technological solutions. After that an assessment has to be made as to whether these solutions lead to the improvement of the care provided and the social or human consequences they may have. We have developed some guidelines to make such an assessment, taking into consideration the features typical of primary health care in the evaluation.

We illustrate this approach by applying it to primary health care in the Netherlands. This does, however, not mean that the developments described are typically Dutch and not relevant to other countries. 


\section{The main problems in Dutch primary health care: changes in content and quantity of care}

Basic to an understanding of the main problems in Dutch primary health care are two developments. These are that the workload of the carers has increased over the past years and that the content of the care needed is also changing. These developments are the results of several changes on the demand side (the Dutch population) and on the side of government policies (Fig. 1).

Like other industrialized countries, the Netherlands is faced with an increasing number of people over 65 years of age. Their share in the total Dutch population is growing. The group of elderly people contains relatively more women, oneperson households and people aged over 80 [2]. They make a strong demand upon health care resources. The ageing of the Dutch population affects the state of public health in that the prevalence of chronical and severe diseases rises [3]. Furthermore, the number of terminal patients in primary care has increased [4]. This means that different kinds of health care are needed. As far as this is expressed in a changed demand for health care, the tasks of primary-care providers will have to change too. The focus changes from diagnosis and (to a lesser extent) treatment to prevention, nursing and rehabilitation as the most important functions of primary health care. Furthermore, the need for continuous care will grow: help should be available 24 hours a day.

Apart from these changes in health needs as a result of changes in health status, the propensity to seek care or to express a demand for health care is changing also. People make higher demands upon the quality of life. Health is no longer seen as the absence of a disease but as a state of total physical, psychological and social wellbeing. This extends the scope of health care: more attention must be given to psychosocial problems and more knowledge of the patient's life and

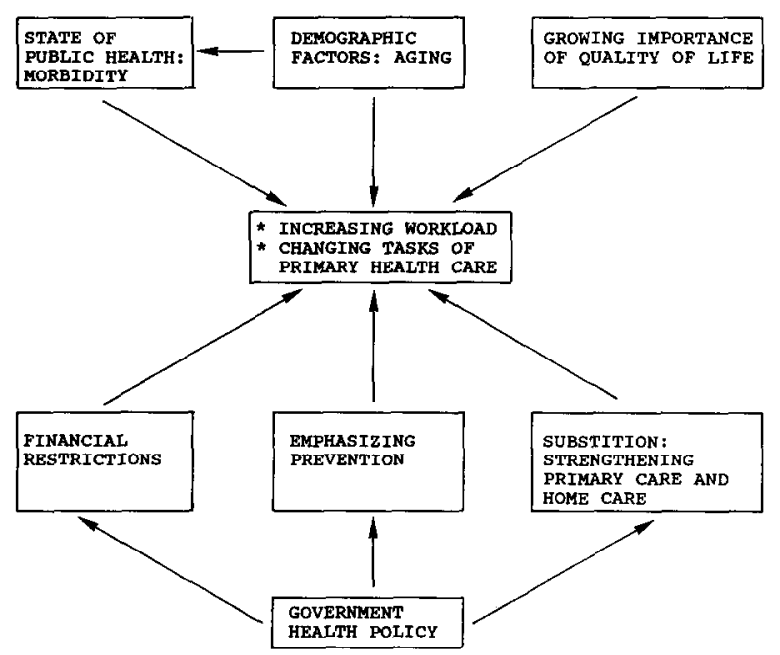

Fig. 1 General developments in Dutch primary health care. 
home situation is needed [5].

On the whole we can say that the health needs of the population will change. This may have consequences on the demand for health services in the sense that they will be confronted with more impaired and disabled people, who need more and different kinds of care.

On the Dutch government side there are some policy changes which also affect the workload and activities of primary care providers. The rising costs of the health services and the increasing emphasis in society on the independence and the personal responsibility of the patient has made policy shifts necessary [6]. The government wants to encourage self care and primary health care. Hospital care should only be used when other kinds of care fail. Carers should pay more attention to the wishes and needs of the patients. This will probably increase the workload of the care providers as well.

As we said, these developments influence the amount and content of primary care. Emphasis shifts from diagnosis and treatment of acute episodes to longterm treatment and nursing, rehabilitation and prevention as functions of primary care. The main problems that primary health care faces are therefore in these latter functions and in the coordination of the different functions.

A problem in long-term treatment and nursing at home is that it is more difficult to monitor the status of the patient and the progression of the disease continuously, than in the hospital situation. Technology used in home care is often very simple, partly outmoded and not available in sufficient quantities, due to budgetary restrictions, which also pose problems of allocation [4].

A new field in rehabilitation is formed by the growing number of chronically ill patients with impairments and disabilities that restrict their activities in everyday life and thus their quality of life. Small adaptations in the home environment can enhance the quality of life considerably [4]. Primary health care must be able to assess these problems and to advise on their solution and implementation.

In the field of prevention, the main problems are organizational and educational. The administration and secretarial equipment in general practice are important conditions for preventive activities. At the moment these conditions are not met in general practice; furthermore, the attitude of general practitioners towards the utility of prevention is not altogether favorable [7]. An important field of primary prevention concerns the prevention of accidents at home; the elderly are a major risk group for these accidents [8]. Primary-care workers who regularly visit patients at home, such as community nurses and family assistants, could be helpful in this field of prevention, provided that their education is pointed to these problems. When the care of patients with different needs is moved to the community setting, coordination between the different carers becomes essential. They have to communicate with each other and exchange important information about particular patients.

It is important that the workers know what they have to do and what is the responsibility of the other professional groups. Primary health care in the Netherlands is suffering form a lack of organization. Carers work in different settings. Some, such as general practitioners, are in independent practice, others, 
like community nurses, are employed by health care organizations. Their practice areas often do not coincide; it is unclear who is responsible for the care of a certain patient.

The changes in content and quantity of care and the associated problems could be solved by increasing the supply of primary health care (capacity of the workers), by setting new priorities and/or by increasing the efficiency of the work. One of the ways to increase efficiency might be the use of new technologies in primary care.

In the next section we will discuss some of the new technologies that come available for primary care. After that we will assess whether new technologies can provide a solution for the main problems in primary health care.

\section{New technologies for primary health care}

In this section we will describe a few of the technological innovations relevant to primary health care in the Netherlands. We distinguish among three types of technology. First, devices that can be used by the patients themselves or by their informal carers, such as wheelchairs and domestic aids. Secondly, 'tools' for the professional care providers: e.g., in the field of diagnosis, treatment or nursing. Another group of technologies is that to improve the coordination of care, e.g., communication techniques.

Recently, an increasing number of aids has become available for the disabled and the elderly $[9,10]$.

Technical aids are developed to control the home environment: e.g., a remote control for opening and closing doors or curtains, picking up the telephone or switching on the television or heating. The 'home bus' is new, this is an information network at home in which different devices are linked with a central computer [11]. Research institutes are working on a 'smart house' which is operated by voice recognition for all everyday activities [9]. There are safety adaptations in the house, such as devices that turn off the gas or electricity supply automatically when it is not going to be used for a longer period.

A lot of research has been done to improve the patients mobility: lightweight collapsible wheelchairs, better crutches and patient elevators have been developed $[9,10]$.

Communication technologies are important in keeping disabled and elderly people from social isolation: the home computer is used as aid for reading, writing and even speaking. Auditory information is introduced in elevators and in devices for self measurement of the blood glucose level [12]. Alarm systems are a special kind of communication technology. They allow the user to call for help if necessary: mostly in an emergency situation. There are different kinds of alarm system. Some make use of portable transmitters, others of fixed devices to transmit the alarm. Some systems contact professionals immediately, others call informal carers first. In some systems it is possible for the user to communicate directly with the help giver, in other systems it is only possible to talk to a 
central unit.

Now we turn to the second group of technologies. Many new 'materials' are developed to ease diagnostic tests. Monoclonal antibodies are being used to make 'diagnostic kits' [13]. Some of these tests can be bought and used by the patients themselves, others are only available for professionals in primary care. Furthermore, diagnostic technology that used to be available only in the hospital setting is now becoming available in primary care. Equipment for echography can be used for the detection of gall stones. Transmission tomography will in future give better images than the current echograms. A portable X-ray device is already available. This makes it possible for a general practitioner to examine people at home [14]. It is possible to do ECGs in community practice. The test results can be sent by telephone to a specialist or can be analyzed by the general practitioner himself. In the Netherlands these instruments are only used on a small scale in community practice.

The possibilities for home treatment have been increasing enormously because of technological innovations. Renal and peritoneal dialysis already take place in the home setting [15]. Respiratory systems are adapted to the specific demands for home use: a new portable 'home-care ventilator' is available [16]. New systems for the automatic administration of nutrition, hormones or drugs are introduced: for example, portable pumps for temporary delivery of drugs and implantable reservoirs which are refillcd through the skin and uscd for long-term or continuous intravenous drug therapy [11]. They can be used for parenteral nutrition of patients with bowel diseases, to supply cytostatic drugs for home chemotherapy, for administrating insulin, or morphine to patients with (chronic) pain.

Another important development in home treatment is 'clinical monitoring'. Several physiological parameters, such as blood pressure, glucose level and heart rate, can be measured automatically with biosensors [17]. The possibilities of feeding these measurements directly into a computer that contacts a professional carer directly in case of an emergency are being investigated. Research is continuing on linking a biosensor for the continuous recording of the medication level in the blood with an automatic drug-administration system. The supply of medication can be controlled. The optimal time to give medication depends upon the circadian cycles of specific patients. The reservoirs are able to deliver the right amount of medication, at the right time [11]. Research on biosensors has not (yet) provided satisfactory results. There are still problems on the selectivity of biosensors and the sensitivity, accuracy and reliability of the measurements [17].

Furthermore, laser technology is finding increasing application in health care recently, especially in eye surgery $[17,18]$. In primary health care 'soft lasers' are beginning to be used in areas such as physiotherapy, i.e., for pain management, treatment of sport injuries and rheumatic impairments. It must be borne in mind, however, that these applications are not (yet) supported by experimental evidence: the effectiveness of laser techniques in health care is still doubtful [17].

Better materials are becoming available for the nursing of patients at home: for instance (electric) adjustable, in height, beds that fit in the home, and improved 
mattresses [10].

Finally we want to mention some new technologies in the field of communication. For adequate professional care, providers need to have relevant information about particular patients and about the treatment by other health care providers. Computer systems are being introduced to record the patients in a general practice. The problem in the Netherlands is, however, that different professions in primary health care use different information systems which are not compatible. It will probably be many years before the integration of the different systems into one health care network is achieved.

A future application of information technology in health care is the so-called 'expert system'. Care providers can consult this system in which information about the disease (symptoms) and the treatment is collected. These kind of systems are still in the development stage.

In practice it will often be impossible to connect all care providers in one computer network. When the patient carries his own 'up to date' medical data, the care provider can get the information needed. In this technical option is the 'smart card', a card with a microprocessor and a data-storage memory, developed originally for use in the financial world. The access to the information on the card is regulated by the microprocessor. A part of the information can be read directly, other information is only accessible for a particular type of user: physician, nurse, pharmacist, etc. Each must give his confidential code number in order to access the authorized zone.

In this section we have described some technological innovations which are or are becoming available for use in primary health care. Next we want to know whether these technologies can lead to the solution of the problems described in the previous section.

\section{The intersection of problems and possible technological solutions}

In the second section we have described the developments that lead to an increasing workload in primary care and a changing content of the needed care. The main problems facing Dutch primary care at this moment are situated in the fields of long-term treatment and nursing, rehabilitation, prevention and the coordination of services. Diagnosis and treatment of acute episodes are relatively less important in the changing situation of primary health care. The technological developments that have been described are partly in the field of diagnostic tools, either directly in the hands of patients or in the hands of the providers of care.

The successful introduction of new technology in primary care depends on a number of general conditions. We mention here the rules and regulations concerning the remuneration of providers and the reimburscment of costs to the patients, the education of primary health care providers and the acceptability of the technology to patients. In Fig. 2 the intersection of problems and technological solutions is summarized.

The new diagnostic technologies do not solve the main problems of primary 


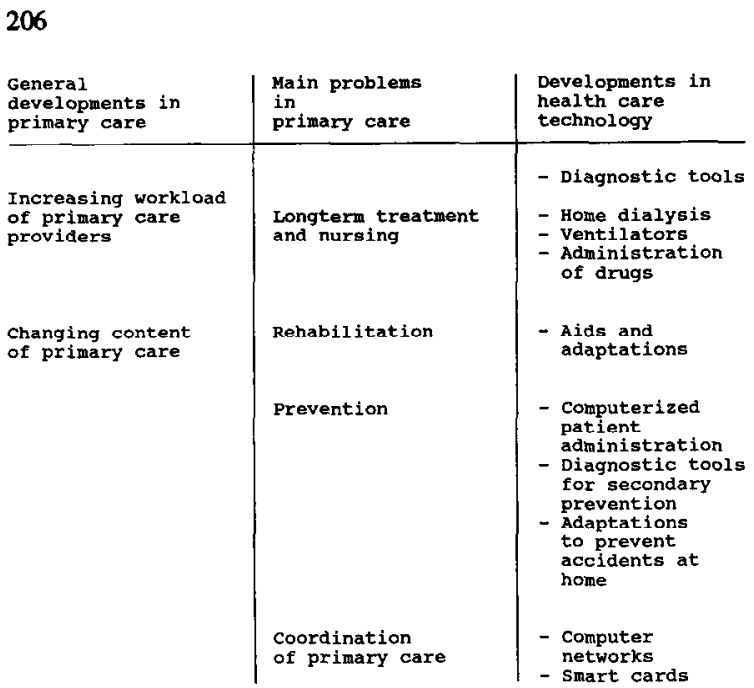

Fig. 2 intersection between problems and new technologies.

care in our analysis. The developments in home dialysis, ventilator systems and administration of drugs are relevant to the improvement of long-term care and nursing. Apart from the general conditions mentioned above, the effectiveness of these solutions to the problems in long-term care and nursing depends on the possibilities of monitoring the status of the patient and the progression of the disease and on the coordination of care between different providers.

The developments in aids and adaptations might improve the possibilities of rehabilitation in the home setting. A condition for the successful application of the new devices is that the care providers have the information necessary to assess and implement possible solutions and that the allocation of resources is adequately organized.

Computerization of the patient administration in primary care, the introduction of adaptations in the homes of the disabled and elderly people to prevent accidents, and diagnostic tools for secondary prevention may contribute to the improvement of prevention activities. Important conditions in this field are changes in practice organization and in the general attitude towards prevention of the care providers.

Finally, the development of communications technology is relevant to the improvement of care coordination. The usefulness of the developments partly depends on the possibility of integrating the communications technology in networks. Systems have to be standardized.

In summary, we can conclude that a number of technologies may contribute to the solution of problems in Dutch primary health care. It is, however, not sure that the implementation of these innovations improves the quality of the care. There may be side effects from the use of technology. We have to consider the possible consequences of the implementation of technology in primary care before deciding whether it is worthwhile doing. This evaluation is the subject of the next section. 


\section{The evaluation of new technologies in primary health care}

Technology assessment in health care contains several kinds of evaluations: testing the clinical safety and efficacy, the assessment of costs and benefits and the study of social conditions and consequences of the introduction of a technology [19]. Here we restrict ourselves to the social consequences, although the clinical and economic aspects of a technology also will have to be reassessed on introduction into primary care. The main reason for this restriction is that, so far, less attention has been paid to these social aspects, although they are very important in the primary care setting.

In general, a technology may have consequences at five different social levels: the community (the direct social environment of the patient), the patient, the care providers, the health care system and society at large. It is necessary to determine the main aspects for evaluation at the different levels themselves and for the relations between these levels for a systematic investigation of the social and human implications of a technology.

In the next figure we present the topics which should be part of the evaluation of a technology in primary health care.

Research in the hospital setting suggests that the increased use of advanced technology leads to higher anxiety in patients, a reduction of mobility, and feelings of depersonalization [20]. Some technologies reduce the patients' freedom of choice (e.g., the case of non-portable equipments for home treatment), others may improve the autonomy of the patient (a wheelchair for disabled). Another

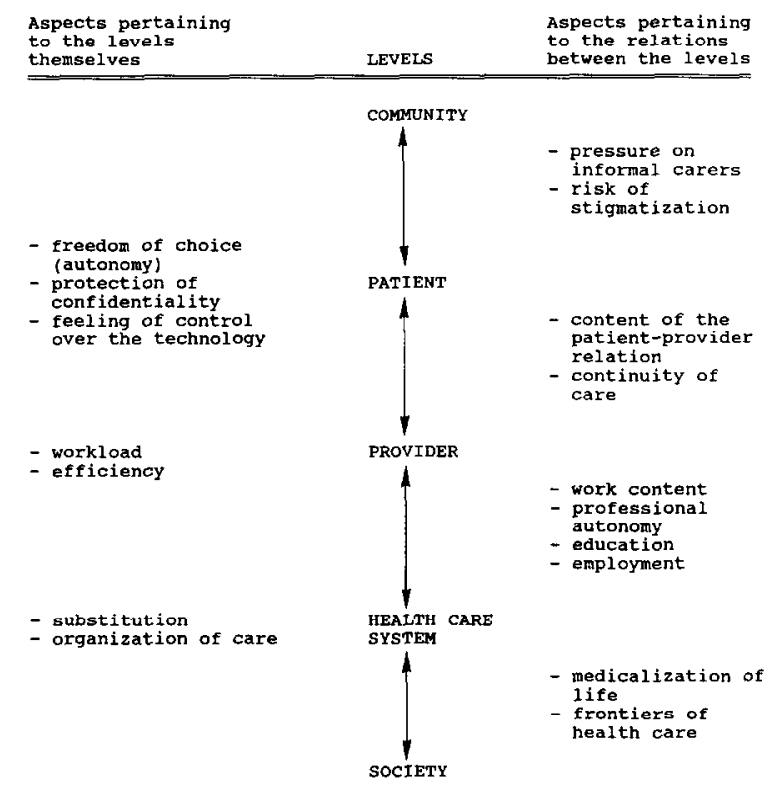

Fig. 3 Relevant aspects for assessments of technologies in primary care. 
important point is the protection of confidentiality [21]. Understanding the working of the equipment is important for the feeling of control over technology.

A technology can lead to a decrease of the workload of professional care providers because their work is more efficiently organized. We have to keep in mind, however, that it is also possible for their workload to increase, because more can be done in primary care. The availability of new technologies can also change the content of the providers' work.

The main point of attention at the level of the health care system is the question of whether the new technology contributes to the realization of policy goals like substitution. Furthermore, the introduction of technology does not end with implementation of techniques or use of the equipment alone. In most cases adaptations in the organization of (parts of) the health care system are required: e.g., in the case of allocation systems to be developed for the introduction of new devices.

The influence of a technology on the relationship between the patient and his/her social environment can be assessed in terms of the pressure on the informal carers, especially when techniques are introduced in the home situation, and the risk of stigmatization. It is often reported that the use of devices, such as a wheelchair or crutches by disabled people, give rise to a stigma and that this causes problems in the field of social relations [22].

The use of technology might affect the content of the paticnt-care-provider relation. The use of advanced technology limits the direct communication between care givers and patients [23]. It might also affect the continuity of care because more (specialist) professionals become involved in the care of one patient.

Aspects affected on the relation between the professional workers and the health care system as a whole are: consequences for the professional autonomy of the individual worker, the necessary changes in the education and training of the workers and the influence of the use of technology on the amount of employment in health care.

In the relation between the health care system and society at large, investigations have to be made into the consequences of the introduction of new technologies for value orientations relating to what human and social problems should be regarded as health problems (medicalization) and to the limits of health care.

In using this scheme, attention is not restricted to the outcome effects of technology, such as change in health status or quality of life; attention is also paid to interactive effects on patients and community, organization and so on [24].

Of course these aspects of the social consequences are not necessarily relevant to every technology in primary health care. However, Fig. 3 provides a framework for directing attention to an all-encompassing evaluation of the consequences of the introduction of technology at different social levels. Before this framework can be used in the actual assessment of new technologies, the points of attention have to be transformed to criteria to measure the impact of the technologies studied. 


\section{Discussion}

Technology tends to devolve upon primary health care in an unplanned way, directed mainly by the availability of new technologies and not by the needs of primary care. In this paper we have described an approach which takes as a starting point the main problems in primary health care and looks at the contribution that technology might give to the solution of these problems. This problem oriented approach constitutes a more rational basis for decisions about adopting or refusing (new) technologies in health care. The primary function of this rational approach is to limit the set of technological possibilities to those that have a clear relevance to primary care: the technologies that can improve the quality of care or/and the efficiency of the work of the care providers.

A broad assessment is required to find out which technologies really contribute to the improvement of primary health care. In addition to the medical and economic aspects, the social impact of the introduction of technologies in primary care has to be studied. A framework has been developed that takes into account the patient in relation to his/her social environment and to the providers of health care and the broader society to direct such studies.

Decisions about the use of technologies are being made at different levels: general decisions by policy makers or financers of health care and more practical decisions by the individual care providers or by the patients themselves. In fact the most important level is that of the providers of health care, who somehow start to believe that a technology is beneficial (either to themselves or to their patients or both). However, the aggregate effects of these decisions may be beyond the scope of the individual care providers. Policy makers have to decide whether and how the use of a technology is to be paid for. These decisions, however, must not be taken in isolation from those who provide care.

The problem-oriented approach is important as a connection between health policy makers and the day to day reality of health care. As far as problems are recognized in the health care field it facilitates the possibilities of implementing change. It is therefore important to involve health care providers in the formulation of the main problems to be solved.

The possibilities of implementing policies concerning the introduction of new technology in primary care are restricted. The most important policy tools are the selcctive regulation of financing technologies within the social sccurity and health care system.

By a broad investigation of the different consequences of the introduction of a technology, the pros and contras at different social levels can be weighed. This may lead to more rational decisions about the development and diffusion of (new) technologies in primary health care.

\section{Acknowledgement}

This study was financed by the Netherlands Ministry of Welfare, Public Health and Cultural Affairs. An earlier version of this article was presented at the Fifth 
Annual Meeting of the International Society of Technology Assessment in Health Care, London, June 5-6, 1989.

\section{References}

1 Sjönell, G., The impact of new technologies in primary health care, Intemational Journal of Technology Assessment in Health Care, 5 (1989) 73-77.

2 CBS (Centraal Bureau voor de Statistiek), Prognose van de bevolking van Nederland na 1980 , Deel 1: uitkomsten en enkele achtergronden, Staatsuitgeverij, 's Gravenhage, 1982.

3 Schellekens, J.W.G., Van de Hoogen, HJ.M. and De Vries, P.E., Morbiditeit nu en in de toekomst: consequenties voor de huisarts. In W.G.W. Boerma and L. Hingstman (Eds.), De eerste lijn onderzocht, van Loghum Slaterus, Deventer, 1985.

4 STG (Steering Committee on Future Health Scenarios), Anticipating and Assessing Health Care Technology, Vol. 8, Potentials for Home Care Technology, Kluwer Academic Publishers, Dordrecht/Boston/London, 1988.

5 NIVEL, Naar een sterkere eerste lijn? Deel $1 \mathrm{t} / \mathrm{m} \mathrm{4}$, NIVEL, Utrecht 1987/1988.

6 Ministerie van Welzijn, Volksgezondheid en Cultuur, Nota Volksgezondheidsbeleid bij beperkte middelen, Staatsuitgeverij, 's Gravenhage, 1983.

7 Bensing, J.M. and Van der Zee, J., Stand van zaken 1985, Momentopname van het eerste lijnsonderzoek. In E.M. Sluijs, J.P. Dopheide and J. van der Zee (eds.), Overzichtsstudie onderzoek eerste lijn, stand van het wetenschappelijk onderzoek in en over de eerstelijnsgezondheidszorg en haar raakvlakken, NIVEL, Utrecht, 1985.

8 Thien, W.M.A.H., Emst en omvang van ongevallen bij ouderen. In W.HJ. Rogmans, W.M.A.H. Thien and R.J. van Zonneveld (eds.), Veilig op leeftijd, veiligheid voor ouderen in en om de woning. Stichting consument en veiligheid, VUGA - Uitgeverij, Amsterdam, 's Gravenhage, 1987.

9 RIC (Revalidatie Informatie Centrum), Inventarisatie van onderzoek op het gebied van de revalidatie in Nederland, RIC, Hoensbroek, 1987.

10 ISG (Interdepartementale Stuurgroep Gehandicaptenbeleid), Overzicht van lopend onderzoek bekend bij of gesubsidièerd door de departementen, ISG, Rijswijk, 1986.

11 Vigier, J.P., Developing, Deploying, Using and Maintaining Technologies at Home, European Health Policy Forum Seminar, Brussels, 1988.

12 TUE/BMGT (Technische Universiteit Eindhoven), Info 16, 1987.

13 Scherstén, T., Home Diagostic Tests, International Journal of Technology Assessment in Health Care, 1 (1985) 441-442.

14 Farell, J. and Carter, E., Portable and hand held X-ray instrument (Lixiscope), International Journal of Technology Assessment in Health Care, 3 (1987) 170-171.

15 Lameire, N.H., Experience with CAPD as home dialysis, International Journal of Technology Assessment in Health Care, 1 (1985) 305-313

16 Teirlinck, C.J.P.M., Apparatuur voor thuisbeademing: stand van zaken en wenselijkheid van een kwaliteits- en gebruikswaarde-onderzoek, MTD-TNO, Leiden, 1987.

17 Gezondheidsraad, Medische technologie, advies in hoofdlijnen, Gezondheidstaad, 's Gravenhage, 1987.

18 STG (Steering Committee on Future Health Scenarios), Anticipating and assessing health care technology, Vol. 1, General considerations and policy conclusions, Martinus Nijhoff Publishers, Dordrecht/Boston/Lancaster, 1987.

19 IOM (Institute of Medicine), Assessing medical technologies, National Academy Press, Washington $\mathrm{DC}, 1985$.

20 De Vries - Griever, A.H.G., Schnidt, S.H., Van Ekeren, C., Meijman, T.F., Techniek en patiëntenzorg: een arbeidspsychologische studie naar de invloed van nieuwe technologieën op de inhoud van het verpleegkundig werk in ziekenhuizen, RUG, vakgroep arbeidspsychologie, Groningen, 1987.

21 Haas, J. and Mehnert, W.H., Ethical considerations in the use of cancer registry data for technology assessment, International Joumal of Technology Assessment in Health Care, 2 (1986) 311-315. 
22 Blaxter, M., The meaning of disability, a sociological study of impairment, Heineman, London, 1980.

23 King, R.C., Technology and the doctor - patient relationship, International Joumal of Technology Assessment in Health Care, 3 (1987) 11-18.

24 Glasser, J.H. and Chrzanowski, R.S., Medical technology assessment, adequate questions, appropriate methods, valuable answers, Health Policy, 9 (1988) 267-276. 